
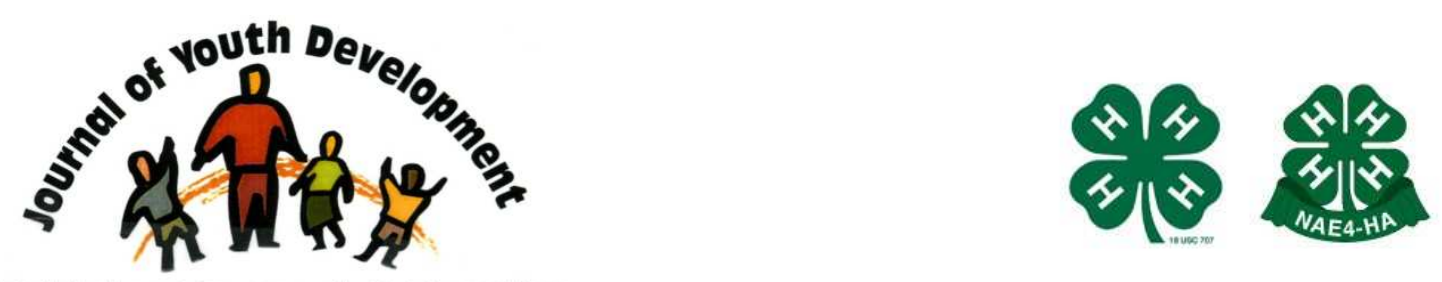

Bridging Research \& Practice

\title{
Parenting Style and the Timing of Jewish Adolescents' Sexual Debut
}

\author{
Robby Etzkin \\ Jewish Community Association of Austin Center \\ Austin, TX \\ Robby.Etzkin@ShalomAustin.org \\ Rosemary V. Barnett \\ Department of Family, Youth \& Community Sciences \\ University of Florida \\ Gainesville, FL \\ rbarnet@ufl.edu \\ Suzanna Smith \\ Department of Family, Youth \& Community Sciences \\ University of Florida \\ Gainesville, FL \\ sdsmith@ufl.edu \\ Stuart E. Schwartz \\ Department of Special Education \\ National University \\ LaJolla, CA \\ sschwartz@nu.edu \\ Eboni J. Baugh \\ Department of Family, Youth \& Community Sciences \\ University of Florida \\ Gainesville, FL \\ ejbaugh@ufl.edu
}




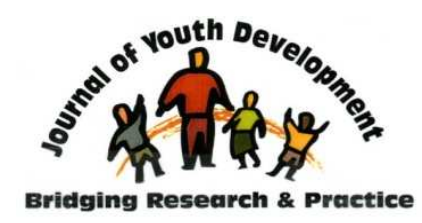

\title{
JOURNAL OF YOUTH DEVELOPMENT \\ bridging research and practice

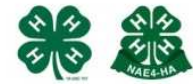

Volume 5, Number 2, Summer 2010

Article 100502FA001

\section{Parenting Style and the Timing of Jewish Adolescents' Sexual Debut}

\author{
Robby Etzkin \\ Jewish Community Association of Austin Center \\ Rosemary V. Barnett, Suzanna Smith and Eboni J. Baugh \\ University of Florida \\ Stuart E. Schwartz \\ National University
}

\begin{abstract}
Parenting style and its effect on the timing of Jewish adolescents' sexual debuts were examined in the reported study. One hundred sixty-eight research participants between the ages of 18 and 22 from a large university in the Southeast participated in the study. A survey instrument was administered at three fraternities and two sororities to examine parenting style and sexual debut retrospectively. Data were analyzed using descriptive statistics, frequency chi square tests, and Analysis of Variance (ANOVA); while post hoc results were determined through Tukey's honestly significant difference.
\end{abstract}

Results found that authoritative parenting provides a delay in the age of sexual debut for Jewish adolescents. All other parenting styles had mean ages less than the overall mean age of sexual debut, 17.10 years old, with indifferent parenting having the earliest debut. These findings suggest that parenting style may affect the timing of Jewish adolescents' sexual debut. The study has implications for understanding factors that may affect the timing of a Jewish adolescent's sexual debut and may help parents protect their adolescent from the negative effects associated with early sexual debut, such as low academic achievement. Recommendations for future research include exploring the effects of family structure and peer networks to understand fully the many factors that affect the timing of adolescents' sexual debut. 


\section{Introduction}

Human sexual activity is inherently related to many of the social and public health concerns in the United States today (CDC, 2007; Calhoun \& Friel, 2001). Early adolescent sexual activity has long been viewed as another case of problematic behavior (Jessor, et al., 1983; Meschke \& Silbereisen, 1997). These concerns stem from the potential risks which include early unintended pregnancies, sexually transmitted diseases (Calhoun \& Friel, 2001), and a high cost to society (Haurin \& Mott, 1990). In 2007, the Center for Disease Control (CDC) reported that " $48 \%$ of high school students had ever had sexual intercourse" and that "15\% of high school students had had four or more sexual partners." As a result of early sexual behaviors by teens, public costs associated with welfare and other target programs have been well documented (Haurin \& Mott, 1990; Hofferth, 1987). Costs to the individual in the form of lower educational and economic prospects and poor health have also been established (Haurin \& Mott, 1990; Strobino, Grason, \& Minkovitz, 2002).

This paper discusses a study which examined parenting style and whether it has an effect on the timing of Jewish adolescents' sexual debut. Many studies have studied the timing of adolescent sexual debuts (Noell \& Biglan, 1995; Rosenthal \& Feldman, 1999; Whitbeck, Yoder, Hoyt, \& Conger, 1999; Jackson, Barnett, Smith \& Gibson, 2010). Studies have also examined the timing of sexual debut among racial and ethnic minorities (Brewster, Billy, \& Grady, 1993; Gillmore, et al., 2002; Upchurch, Aneshensel, Sucoff, Levy-Storms, 1999). However, there is only a small collection of studies on the timing of adolescents' sexual debut among religious minorities (Brewster, Billy, \& Grady, 1993; Reed \& Myers, 1991; Thornton \& Camburn, 1989). Furthermore, there is an absence of literature specifically pertaining to Jewish adolescents' sexual debut.

\section{Literature Review}

Adolescents are having sex at younger ages; therefore, they continue to make themselves vulnerable to potential pregnancies and sexually transmitted diseases. Well over half, $60.5 \%$, of high school seniors report that they have had sex. The age of sexual debut has been steadily decreasing, the number of sexual partners before age 18 has been increasing, and only one in five adolescents remain virgins by the time they are twenty years old (Calhoun \& Friel, 2001; Laumann, Gagnon, Michael \& Michaels, 1994). The young adolescent is usually unprepared for difficult relationship decisions associated with close intimacy (Day, 1992), and because of their undeveloped decision-making process, they may not be able to realize the potential health and economic costs of their actions. Given these recent trends, adolescent sexuality continues to be an important area of research.

\section{Parental Communication, Parenting Style, and Gender}

Parents can directly reduce the risks their children face by encouraging them to avoid unprotected intercourse and by monitoring their behavior (Luster \& Small, 1994). Despite belief that parents should be the primary source of information about sexuality, they usually are not (Abrams, 1990; Ansuini \& Fidder-Woite, 1996; Rosenthal \& Feldman, 1999; Rosenthal \& Smith, 1995). When parents communicate about sexuality, they focus on issues relating to physical development and sexual safety rather than psychological, relationship-based topics, or those which might be considered personal, such as practicing safe sex and emotion-based intimacy (Baldwin \& Baranoski, 1990; Rosenthal \& Feldman, 1999; Rosenthal \& Smith, 1995). Most parents find the task of providing sex education for their children daunting and one for which 
they feel ill-equipped (Rosenthal \& Feldman, 1999; Rosenthal \& Smith, 1995) and few provide detailed sex education with many not broaching the topic at all (Inazu \& Fox, 1980; Kahn et al., 1985). There is a clear gap between what parents know they should do and what they are actually doing.

Although poor communication with parents and lack of parental support predicts early adolescent sexual activity, delayed debut is associated with high levels of parental monitoring and open parent-child communication about sexual issues (Levin, Xu, \& Bartkowski, 2002). The discussion of sex seems to delay sexual activity primarily among daughters of traditional parents (Moore, Peterson, \& Furstenberg, 1986) and researchers have concluded that parental communication decreases sexual activity (Inazu \& Fox, 1980; Meschke \& Silbereisen, 1997). However, findings on this topic have been mixed with some researchers finding no consistent effects of parental communication (Miller \& Moore, 1990).

Parents who use less power-oriented means of control tend to have children who exhibit more socially appropriate behavior on a number of indicators (Miller, McCoy, Olson, \& Wallace, 1986) including age of sexual debut. Parental monitoring and harsh discipline have consistently been shown to affect other minor deviant behaviors that are highly correlated with early sexual intercourse (Simons, Johnson \& Conger, 1996; Whitbeck et al., 1999). Some parenting styles seem to be more successful than others; teens who view their parents as over controlling exhibit a greater number of sexual risk-taking behaviors (Barber, 1992; Rogers 1999). Sexual intercourse is most likely to occur among adolescents who have the most autonomy to date whom they want, to date at an early age, and to control their own dating activities (Miller, McCoy, Olson \& Wallace, 1986). High levels of parental supervision (Hogan \& Kitagawa, 1985) and a close relationship between adolescents and their parents significantly predicted the later timing of adolescent sexual activity (Meschke \& Silbereisen, 1997).

On the other hand, excessive strictness and rules might increase the risk of having sexually permissive children (Miller, McCoy, Olson \& Wallace, 1986). Closer parent-child relationships are associated with delayed sexual debut but not pregnancy experience (Moore \& ChaseLansdale, 2001; Resnick, et al., 1997). It is more important if this close parent-child relationship is characterized as close by the child rather than by the parent. Adolescents who perceive their parents as being supportive and emotionally close report less sexual risk-taking behaviors (Luster \& Small, 1994; Rogers, 1999). A close parent-child relationship is also important because poor parent-child relationships have greater effects on timing of first intercourse than do positive parent-child relationships (Whitbeck, Yoder, Hoyt, \& Conger, 1999). Positive parental communication and monitoring are protective factors for all adolescents academically, emotionally, and sexually. Parental discussion of sexual issues with their adolescent may provide a delay in the onset of their adolescent's sexual debut (Inazu \& Fox, 1980; Meschke \& Silbereisen, 1997).

\section{Gender}

One reason parents fail as sex educators may be their biased sexual communication patterns. Parents, especially mothers, tend to tailor their communications to be gender-appropriate (Rosenthal \& Feldman, 1999), thus neglecting feminine issues for boys and masculine issue for girls. Girls receive more information than boys about such topics as menstruation, abortion, pregnancy, and sexual pressure, and less information on topics such as masturbation and wet dreams (Rosenthal \& Feldman, 1999). In addition, parents are less likely to discuss sex with sons than with daughters (Kahn et al, 1985; Rosenthal \& Feldman, 1999). 
Different methods appear to work for each gender, with daughters having lower incidence of sexual activity when parents discuss sex and/or sexual television programming with them. With sons, traditional parents tend to listen and discuss decisions, which are related to lower probability of sexual activity. However, discussion is associated with a greater likelihood that sons were sexually experienced (Moore, Peterson \& Furstenberg, 1986). This clearly illustrates a discrepancy between effective communication and gender.

Factors associated with sexual risk taking among females include low GPA, frequent alcohol consumption, low levels of parental monitoring, and a lack of communication about birth control with mothers. For males, in addition to low GPA, factors include frequent alcohol consumption, suicidal ideations, low levels of parental support, and a history of sexual abuse (Luster \& Small, 1994). Males are also said to experience peer pressure to engage in sexual activity (Udry \& Billy, 1987). Although other factors may have minor influences (e.g., the suppressing effects of pro-social activities for girls), the important predictors seem to be lack of parental supervision and monitoring (parenting style) and parents' communication.

\section{Research Questions}

1. Is there a difference in the timing of sexual debut among Jewish adolescents raised with different parenting styles?

2. Do any of the four parenting styles positively affect (delay) the timing of Jewish adolescents' sexual debuts?

3. Do any of the four parenting styles negatively affect (expedite) the timing of Jewish adolescents' sexual debuts?

\section{Methodology}

This study focused on examining parenting style and its affect on the timing of Jewish adolescents' sexual debut.

The population consisted of Jewish students at a large southeastern university. Potential participants were identified through the University's predominantly and/or historically Jewish fraternities and sororities. The final sample consisted of Jewish undergraduate students who elected to participate $(\mathrm{N}=168)$. After approval from the university IRB, participants were informed of the study at weekly chapter meetings in their fraternity or sorority house. Once participants gave consent, they completed a survey and identification numbers were assigned to protect identity. Data analysis was conducted after the surveys had been randomly mixed.

The survey instrument consisted of 25 items divided into a personal information section and two content sections. The data set was split into two groups: the first group of respondents answered "Yes" to having had sex $(n=121)$ and the second group answered "No" to having had sex $(n=47)$. The two groups allowed for analyses of those respondents who have experienced their sexual debut and the factors that affected it's and also a description of the virgin group.

The sample population was mostly male (53\%) due to data collection at three fraternity houses, compared to two sorority houses. All of the study participants were Jewish, half were Conservative (50.0\%), and followed by Reform (45.2\%), Orthodox (2.4\%), and Other (2.4\%). Seventy two percent reported having previously had sex, and the mean age of sexual debut was 17.10 years. 
Age at first date and first serious relationship. Fifteen years old was the most common $(31.5 \%)$ age at first date while $3 \%$ reported not yet being on a first date. The vast majority $(95.8 \%)$ reported there were no restrictions on the age at which they could first date. A small percentage (3.6\%) said they were 13 years old when they had their first serious relationship, while $17.3 \%$ said they had not yet been in a serious relationship.

Parental sexual communication. When asked whether parents discussed sex with them, $49.4 \%$ said both parents did. Topics most frequently discussed were physical development $(53.8 \%)$, abstinence $(54.7 \%)$, safe sex $(89.8 \%)$, emotion-based intimacy $(51.6 \%)$, and consequences (83.6\%). Also of interest was age at first sexual discussion with $13(28.3 \%)$ being the most frequent. Participants reported that discussions occurred more than once (45\%). Regarding depth of the sexual discussion, $60 \%$ reported very in-depth or in-depth. Concerning the content of sexual discussion (physical development, abstinence, safe sex, emotion-based intimacy, and consequences), 9.4\% reported only discussing one topic, $21.9 \%$ two topics, $21.1 \%$ three topics, $21.9 \%$ four topics, and $25.8 \%$ reported discussing all five topics.

\section{Parenting Style}

The highest number of respondents believed their parents' parenting style was permissive $(45.8 \%)$. In regards to influence of parenting style on their decision to have sex, $8.3 \%$ responded a very strong influence on their decision, $19.6 \%$ responded a strong influence, $32.1 \%$ responded at least some influence, $25.6 \%$ said very little influence at all, and $14.3 \%$ said no effect at all.

Research question 1. For those respondents who had experienced their sexual debut $(n=121), 41.1 \%$ classified their parents' parenting style as Permissive (see Table 1$). A$ significant relationship $(\mathrm{f}=6.42, \mathrm{p}<.001$ ) was found among parenting styles with respect to mean age of sexual debut. Tukey's Honestly Significant Difference (HSD) test was used to test all possible pairwise comparisons between parenting styles and the mean ages of each parenting style (Table 2). Two significant relationships were found, the first between permissive and authoritative parenting styles and the second between indifferent and authoritative parenting styles (Table 3).

Table 1

Mean and standard deviation of group who experienced sexual debut $(\mathrm{N}=121)$

\begin{tabular}{|l|c|c|c|}
\hline & $\mathrm{N}$ & Mean & Std. Deviation \\
\hline Parenting Styles & 51 & 16.88 & \\
Permissive & 13 & 16.69 & 1.64 \\
Authoritarian & 9 & 15.55 & 1.44 \\
Indifferent & 48 & 17.73 & 1.74 \\
Authoritative & $\mathbf{1 2 1}$ & $\mathbf{1 7 . 1 0}$ & 1.38 \\
Total & & & $\mathbf{1 . 6 3}$ \\
\hline Sexual Debut & 74 & 17.16 & \\
Male & 47 & 17.00 & 1.80 \\
Female & $\mathbf{1 2 1}$ & $\mathbf{1 7 . 1 0}$ & 1.34 \\
Total & & & $\mathbf{1 . 6 3}$ \\
\hline
\end{tabular}


Table 2

Post-hoc evaluation of significant differences of mean age of sexual debut between parenting styles.

Dependent Variable: reference point

Tukey HSD

\begin{tabular}{|l|l|c|c|c|}
\hline $\begin{array}{l}\text { Parenting Style } \\
(\mathrm{I})\end{array}$ & $\begin{array}{l}\text { Parenting Style } \\
(\mathrm{J})\end{array}$ & $\begin{array}{c}\text { Mean } \\
\text { Difference } \\
(\mathrm{I}-\mathrm{J})\end{array}$ & $\begin{array}{c}\text { Standard } \\
\text { Error }\end{array}$ & Sig. \\
\hline Permissive & Authoritarian & .19 & .48 & .98 \\
& Indifferent & 1.33 & .55 & .08 \\
& Authoritative & -.83 & .31 & .08 \\
\hline Authoritarian & Permissive & -.19 & .48 & .98 \\
& Indifferent & 1.14 & .66 & .32 \\
& Authoritative & -1.04 & .48 & .14 \\
\hline Indifferent & Permissive & -1.33 & .55 & .08 \\
& Authoritarian & -1.14 & .66 & .32 \\
& Authoritative & -2.17 & .56 & $.00\left(^{*}\right)$ \\
\hline Authoritative & Permissive & .85 & .308 & $.03\left(^{*}\right)$ \\
& Authoritarian & 1.04 & .48 & .14 \\
& Indifferent & 2.17 & .56 & $.00\left(^{*}\right)$ \\
\hline
\end{tabular}

Note. $\mathrm{P}<.05=*$

Research question 2. Authoritative is the only parenting style that has a mean greater than the overall mean of sexual debut for the study, 17.10 years old. Significant statistical differences were found for permissive and indifferent parenting styles when compared to the authoritative parenting style (Table 2). It should be noted that, according to the survey instrument, the permissive and indifferent parenting styles both lack parental demandingness, which the instrument defines, as parent(s)/guardian(s) setting high standards and insisting that their children meet them. Therefore, it may be a single characteristic within a parenting style rather than an overall parenting style that affects the mean age of sexual debut.

Table 3

Comparison of mean age of sexual debut among variables under study ANOVA

\begin{tabular}{|l|c|c|r|r|r|}
\hline & $\begin{array}{c}\text { Sum of } \\
\text { Squares }\end{array}$ & $\begin{array}{c}\text { Degrees of } \\
\text { Freedom }\end{array}$ & $\begin{array}{c}\text { Mean } \\
\text { Square }\end{array}$ & $\mathrm{F}$ & Sig. \\
\hline Parenting Styles & 45.05 & 3 & & & \\
Between Groups & 273.77 & 117 & 15.02 & 6.42 & $.00\left(^{*}\right)$ \\
Within Groups & 318.81 & 120 & 2.34 & & \\
\hline Total & .76 & 1 & .76 & & \\
\hline Gender & 318.05 & 119 & 2.67 & .28 & .60 \\
Between Groups & 318.81 & 120 & & & \\
Within Groups & & & & \\
Total
\end{tabular}

Note. $\mathrm{P}<.05=*$

Research question 3. A oneway ANOVA test and each mean was compared to that of the overall mean of sexual debut for the study, 17.10 years old (Table 3). Three out of the four parenting styles (permissive, authoritarian, and indifferent) had negative effects on sexual 
debut. The two parenting styles that have the greatest negative effect are authoritarian and indifferent (Table 2).

\section{Additional Results}

\section{Parenting Style}

Significant relationships $(f=4.95, p<.05)$ were found between age at first date, age of first serious relationship, and age of first sexual discussion on mean ages of sexual debut. Therefore, all three had an effect on the timing of sexual debut. Frequency of sexual discussion $(f=3.36, p<.05)$ and how in-depth the sexual discussion was $(f=3.18, p<.05)$ also provided a significant relationship when comparing mean ages of sexual debut.

\section{Virgins}

A statistically significant relationship was found using chi-square test between respondents who had restrictions on the age they could first date $(n=3)$ and respondents who had no restrictions on the age they could first date $(n=44)$. Another significant relationship was found among responses for age at first serious relationship, with 24 respondents claiming to never have been in what they would consider a serious relationship. In addition, significant relationships were found among responses on sexual discussion, frequency of sexual discussions, and depth of sexual discussions prior to the respondent's reference point which for virgins would be their current age. For virgins who had a sexual discussion $(n=35)$, all but 6 had the discussion at age 13 or younger. For the number of sexual topics discussed for virgins, an average of almost three topics ( $u=2.81, S D=1.95$ ) were discussed, indicating that discussing at least three topics may be a protective factor in the timing of Jewish adolescents' sexual debut. Parenting style for the majority of virgins was permissive $(55.3 \%)$ and authoritative (31.9\%). Finally, a significant relationship $(p<.05)$ was found among responses to the question on influence of parenting style and decisions to not have sex.

\section{Discussion}

\section{Parenting Style}

This study can conclude that parenting style does have an effect on Jewish adolescents' timing of sexual debut. This finding is consistent with previous findings for adolescents that differences in levels of parental demandingness and responsiveness may affect adolescent outcomes (Baldwin \& Baranoski, 1990; Levin, Xu, Bartkowski, 2002; Rosenthal \& Feldman, 1999; Rosenthal \& Smith, 1995). Authoritative parenting style, which produced the highest mean age of sexual debut (17.73), is high on both parental responsiveness and parental demandingness (Baumrind (1996, 1978). Both indifferent and permissive parenting styles are low on parental demandingness. It is possible that Jewish adolescents whose parents set high standards for them and insist that their children meet them, may have a later sexual debut than those Jewish adolescents whose parents do not.

When looking for parenting styles that may negatively affect the timing of Jewish adolescents' sexual debut, the largest difference appears with the indifferent parenting style. Indifferent parents minimize the time and energy spent interacting with their child. Adolescents with indifferent parents are less likely to encounter positive outcomes then their peers with other parenting styles (Luster \& Small, 1994; Meschke \& Silbereisen, 1997; Rodgers, 1999; Whitbeck, Yoder, Hoyt, \& Conger, 1999). This study's finding of adolescents with indifferent parents having an early sexual debut is consistent with other studies' findings. 
With parents who are not demanding or responsive, the adolescent has opportunities to make decisions on their own. It has been found that sexual intercourse is most likely to occur among adolescents who have the most autonomy (the least parental control) to date whom they want, to date at an early age, and to control their own dating activities (Miller, McCoy, Olson \& Wallace, 1986). Adolescents raised in indifferent homes are often impulsive and more likely to be involved in delinquent behavior and premature experiments with sex, drugs, and alcohol (Fuligni \& Eccles, 1993; Kurdeck \& Fine, 1994; Lamborn et al., 1991; Pulkkinen, 1982; Steinberg, et al., 1994). This study's findings are consistent with previous research, not only for the indifferent parenting style having the worst outcome, but as well for the authoritative parenting style having the best outcome.

\section{Gender}

It cannot be concluded that gender has an effect on Jewish adolescents' timing of sexual debut. This is consistent with the previous analysis of mean ages of sexual debut by gender.

\section{Limitations}

Each fraternity and sorority house at which data were collected allowed the study to be conducted at their house under the condition that it was voluntary, which may have contributed to the total number or respondents being low. In addition, the study was conducted at three fraternity houses and two sorority houses contributing to a slightly uneven gender distribution. Furthermore, the study focused on adolescent and sexual topics and personal information. This may have caused some respondents to not be as forthcoming and may have caused respondents to not always be truthful in all of their responses. Finally, respondents were asked to remember their decisions and their surrounding environment at the age of their sexual debut and to recall conversations with parents about sex, possibly as much as ten years before the survey. This delay could introduce some inaccuracy in reporting.

\section{Implications for Practice}

The present study has essential implications for Jewish parents, adolescents, communities, and youth workers. Many findings of this study suggest ways that Jewish parents can protect their adolescents against an early sexual debut, such as controlling the age that their child can first date, the age at which they first discuss sex with their child, the topics that they cover, and, most importantly, their overall parenting style.

Many previous studies show that an authoritative parenting style provides the most likely chances of positive child outcomes in various areas such as academic achievement (Steinberg \& Silk, 2002). This study has shown similar findings in terms of the timing of sexual debut, with authoritative parenting apparently delaying sexual debut. If Jewish parents want to help their adolescents postpone sexual debut, then they must be warm but firm. In summary, Jewish parents must be consistently and realistically demanding of their adolescents as well as responsive and openly communicative in order to be able to protect against early sexual debut.

\section{Recommendations for Future Research}

This study is one of the first to specifically examine Jewish adolescents' sexual debut. After determining that parenting style affects the timing of Jewish adolescents' sexual debut, it is imperative to disseminate these results to afford Jewish parents information to protect Jewish adolescents from an early sexual debut. Some researchers recommend that parents need to 
learn how to provide the right amount of the right information at the right time, whether it concerns academic achievement or sexual development (Rosenthal \& Feldman, 1999). Finally, providing this information directly to Jewish adolescents would create an educational forum based on facts that will help shape their decision making and allow Jewish adolescents to communicate openly and knowingly about sexual topics with their parents and their peers. As adolescents become interested in sex and become biologically capable of reproduction, the need to educate them on sexual topics becomes more important. Future studies might explore the effects of parenting style for non-religious or other faith-based denominations on the timing of adolescent sexual debut. It is particularly important for future research to consider that culture, religiosity, and family dynamics may create a unique dynamic for adolescents and parents that may impact sexual behaviors and outcomes.

\section{References}

Abrams, J. (1990). The parent's guide to teenage sex and pregnancy [Review of Book]. Journal of Marriage and the Family, 105 (18), p. 2222.

Ansuini, C.G., \& Fidder-Woite, J. (1996). The source, accuracy, and impact of initial sexuality information on lifetime wellness. Adolescence, 31 (122), p283.

Baldwin, S., \& Baranoski, M.V. (1990). Family interactions and sex education in the home. Adolescence, $25(99)$, p573.

Barber, B. (1992). Family, personality, and adolescent problem behavior. Journal of Marriage and the Family, 54, 69-79.

Baumrind, D. (1978). Parental disciplinary patterns and social competence in children. Youth and Society, 9, 239-276.

Baumrind, D. (1996). The discipline controversy revisited. Family Relations, 45 4, 405.

Brewster, K., Billy, J., \& Grady, W. (1993). Social context and adolescent behavior: The impact of community on the transition to sexual activity. Social Forces, 71, 713-740.

Calhoun, E., \& Friel, L. (2001). Adolescent sexuality: Disentangling the effects of family structure and family context. Journal of Marriage \& the Family, 63 (3), 669.

Center for Disease Control. (2007). Healthy Youth! Healthy Topics: Sexual Risk Behaviors. Retrieved May 28, 2010 from www.cdc.gov/healthyyouth/sexual behaviors/index.htm.5/28/2010.

Day, R.D. (1992). The transition to first intercourse among racially and culturally diverse youth. Journal of Marriage and the Family, 54, 749-762.

Fuligni, A., \& Eccles, J. (1993). Perceived parent-child relationships and early adolescents' orientation toward peers. Developmental Psychology, 29, 622-632. 
Gillmore, M.R., Archibald, M.E., Morrison, D.M., Wilsdon, A., Wells, E.A., Hoppe, M.J., et al. (2002). Teen sexual behavior: Applicability of the theory of reasoned action. Journal of Marriage \& the Family, 64 (4), 885.

Haurin, R.J., \& Mott, F.L. (1990). Adolescent activity in the family context: The impact of older siblings. Demography, 27, 537-557.

Hofferth, S.L. (1987). Social and economic consequences of teenage childbearing. In S. Hofferth \& C. Hayes (Eds.), Risking the future: Adolescent sexuality, pregnancy, and Childbearing, (Vol. 2, pp.123-144). Washington DC: National Academy Press.

Hogan, D.P., \& Kitagawa, E.M. (1985). The impact of social status, family structure, and neighborhood on the fertility of black adolescents. American Journal of Sociology, 90, 825-855.

Inazu, J.K., \& Fox, G.L. (1980). Maternal influence on the sexual behavior of teenage daughters. Journal of Family Issues, 1, 81-102.

Jackson, Barnett, Smith, \& Gibson. (2010). The effects of religiosity and sibling relationships on the timing of sexual debut. In print: Family Science Review.

Jessor, R., Costa, F., Jessor, L., \& Donovan, J. E. (1983). Time of first intercourse: A prospective study. Journal of Personality and Social Psychology, 44, 608-626.

Kahn, S., Zimmerman, G., Csikszentmihalyi, M., \& Getzels, J. (1985). Relations between identity in young adulthood and intimacy in midlife. Journal of Personality and Social Psychology, 49, 1316-1322.

Kurdeck, L., \& Fine, M. (1994). Family acceptance and family control as predictors of adjustment in young adolescents: Linear, curvilinear, or interactive effects. Child Development, $65,1137-1146$.

Lamborn, S., Mounts, N., Steinberg, L., \& Dornbusch, S. (1991). Patterns of competence and adjustment among adolescents from authoritative, authoritarian, indulgent, and neglectful families. Child Development, 62, 1049-1065.

Laumann, E. O., Gagnon, J. H., Michael, R. T., \& Michaels, S. (1994). The social organization of sexuality. Sexual practices in the United States. Chicago: University of Chicago Press.

Levin M.L., Xu, X., \& Bartkowski, J.P. (2002). Seasonality of sexual debut. Journal of Marriage \& the Family, $64(4), 871$.

Luster, T., \& Small, S. (1994). Factors associated with sexual risk-taking behaviors among adolescents. Journal of Marriage and the Family, 56, 622-632.

Meschke, L.L., \& Silbereisen, R.K. (1997). The influence of puberty, family processes, and leisure activities on the timing of first sexual experience in adolescents. Journal of Adolescence, $20(4), 403$. 
Miller, B.C., McCoy, J.K., Olson, T.D., \& Wallace, C.M. (1986). Parental discipline and control attempts in relation to adolescent sexual attitudes and behavior. Journal of Marriage and the Family, 48, 503-512.

Miller, B., \& Moore, K. (1990). Adolescent sexual behavior, pregnancy, and parenting: Research though the 1980s. Journal of Marriage and the Family, 51, 499-506.

Moore, M.R., \& Chase-Lansdale, L. (2001). Sexual intercourse and pregnancy among African American girls in high-poverty neighborhoods: The role of family and perceived community environment. Journal of Marriage \& the Family, 63 (4), 1146.

Moore, K.A., Peterson, J.L., \& Furstenberg, F.F. (1986). Parental attitudes and the occurrence of early sexual activity. Journal of Marriage and the Family, 48, 777-782.

Noell, J., \& Biglan, A.W. (1995). Does sexual coercion play a role in the high-risk sexual behavior of adolescents and young adults? Journal of Behavioral Medicine, $18(6), 549$.

Pulkkinen, L. (1982). Self-control and continuity from childhood to adolescence. In P. Baltes \& O. Brim (Eds.), Life-span development and behavior(Vol. 4, pp.7-16). New York: Academic Press.

Reed, L.A., \& Meyers, L.S. (1991). A structural analysis of religious orientation and its relation to sexual attitudes. Educational \& Psychological Measurement, 51 (4), 943.

Resnick, M., Bearman, P., Blum, R., Bauman, K., Harris, K., Jones, J., et al. (1997). Protecting adolescents from harm: Findings from the National Longitudinal Study of Adolescent Health. Journal of the American Medical Association, 278, 823-832.

Rogers, K.B. (1999). Parenting processes related to sexual risk-taking behaviors of adolescent males and females. Journal of Marriage and the Family, 61, 99-109.

Rosenthal, D.A., \& Smith, A. (1995). Adolescents' perceptions of their risk environment. Journal of Adolescence, $18(2), 229$.

Rosenthal, D.A., \& Feldman, S. (1999). Personal and social factors influencing age at First sexual intercourse. Archives of Sexual Behavior, 28 (4), 319.

Simons, R.L., Johnson, C., \& Conger, R.D. (1996). Mother's parenting. In R.L. Simons \& Associates (Eds.), Understanding differences between divorced and intact families (pp.45-63). Thousand Oaks, CA: Sage.

Steinberg, L., Lamborn, S., Darling, N., Mounts, N., \& Dornbusch, S. (1994). Over-time changes in adjustment and competence among adolescents from authoritative, authoritarian, indulgent, and neglectful families. Child Development, 65, 754-770.

Steinberg, L.D., \& Silk, J.S. (2002). Parenting adolescents. In M. Bornstein (Ed.), Handbook of parenting ( $2^{\text {nd }}$ ed., Vol. 1). Mahwah, NJ: Erlbaum.

Strobino, D.M., Grason, H., \& Minkovitz, C. (2002). Charting a course for the future of women's health in the United States. Social Science \& Medicine, 54 (5), 839. 
Thornton, A., \& Camburn, D. (1989). Religious participation and adolescent sexual behavior and attitudes. Journal of Marriage and the Family, 51, 641-653.

Udry, J., \& Billy, J. (1987). Initiation of coitus in early adolescence. American Sociological Review, 52, 841-855.

Upchurch, D.M., Aneshensel, C.S., Sucoff, C. A., \& Levy-Storms, L. (1999). Neighborhood and family contexts of adolescent sexual activity. Journal of Marriage \& the Family, 61 (4), 920.

Whitbeck, L.B., Yoder, K.A., Hoyt, D.R., \& Conger, R.D. (1999). Perceived Parental Acceptance as a moderator of religious transmission among adolescent boys and girls. Journal of Marriage \& the Family, 61 (2), 362.

(C) Copyright of Journal of Youth Development $~$ Bridging Research and Practice. Content may not be copied or emailed to multiple sites or posted to a listserv without copyright holder's express written permission. However, users may print, download or email articles for individual use. 